\title{
Hydrogen- and helium-implanted silicon: Low-temperature positron-lifetime studies
}

\author{
Mäkinen, S.; Rajainmäki, H.; Linderoth, Søren
}

Published in:

Physical Review B

Link to article, DOI:

10.1103/PhysRevB.44.5510

Publication date:

1991

Document Version

Publisher's PDF, also known as Version of record

Link back to DTU Orbit

Citation (APA):

Mäkinen, S., Rajainmäki, H., \& Linderoth, S. (1991). Hydrogen- and helium-implanted silicon: Low-temperature positron-lifetime studies. Physical Review B, 44(11), 5510-5517. https://doi.org/10.1103/PhysRevB.44.5510

\section{General rights}

Copyright and moral rights for the publications made accessible in the public portal are retained by the authors and/or other copyright owners and it is a condition of accessing publications that users recognise and abide by the legal requirements associated with these rights.

- Users may download and print one copy of any publication from the public portal for the purpose of private study or research.

- You may not further distribute the material or use it for any profit-making activity or commercial gain

- You may freely distribute the URL identifying the publication in the public portal

If you believe that this document breaches copyright please contact us providing details, and we will remove access to the work immediately and investigate your claim 


\title{
Hydrogen- and helium-implanted silicon: Low-temperature positron-lifetime studies
}

\author{
S. Mäkinen and H. Rajainmäki* \\ Department of Physics, University of Jyväskylä, SF-40100 Jyväskylä, Finland \\ S. Linderoth \\ Laboratory of Applied Physics, Technical University of Denmark, DK-2800 Lyngby, Denmark
}

(Received 30 August 1990; revised manuscript received 13 November 1990)

\begin{abstract}
High-purity single-crystal samples of float-zoned Si have been implanted with 6.95-MeV protons and with $25-\mathrm{MeV}^{3} \mathrm{He}^{2}$ ions at $15 \mathrm{~K}$, and the positron-lifetime technique has been used to identify the defects created in the samples, and to study the effects of $\mathrm{H}$ and $\mathrm{He}$ on the annealing of point defects in $\mathrm{Si}$. The results have been compared with those of proton-irradiated Si. A 100-300-K annealing stage was clearly observed in hydrogen $\left(\mathrm{H}^{+}\right)$-implanted $\mathrm{Si}$, and this stage was almost identical to that in the $p$ irradiated Si. The final annealing state of the $\mathrm{H}^{+}$-implanted $\mathrm{Si}$ started at about $400 \mathrm{~K}$, and it is connected to annealing out of negatively charged divacancy-oxygen pairs. This stage was clearly longer than that for the $p$-irradiated $\mathrm{Si}$, probably due to the breakup of $\mathrm{Si}-\mathrm{H}$ bonds at about $550 \mathrm{~K}$. The $100-\mathrm{K}$ annealing stage was not seen with the He-implanted samples. This has been explained by assuming that almost all vacancies contained $\mathrm{He}$ after the irradiation with ${ }^{3} \mathrm{He}$. Helium is suggested to be released from vacancies at about $600 \mathrm{~K}$, and small He bubbles seem to have grown at temperatures above $800 \mathrm{~K}$. The specific positron-trapping rate for negatively charged monovacancy-type defects in $\mathrm{H}^{+}$-implanted $\mathrm{Si}$ has been found to have a $T^{-0.5}$ dependence, whereas for neutral divacancies and monovacancies in $\mathrm{He}$ implanted $\mathrm{Si}$ no dependence on temperature has been observed.
\end{abstract}

\section{INTRODUCTION}

Both atomic hydrogen and helium in semiconductors are of great technological and scientific interest. ${ }^{1}$ In crystalline silicon, hydrogen is known to have a role of saturating broken chemical bonds. ${ }^{2-5}$ For many years this was believed to be the only (and quite harmless) effect that $\mathrm{H}$ has on the physical properties of $\mathrm{Si}$. In recent years, much interest has been taken in the role of $\mathbf{H}$ in $\mathbf{S i}$ since the discovery of its ability to passivate shallow-level and deep-level defects. ${ }^{3,4,6}$ In $p$-type $\mathrm{Si}, \mathrm{H}$ is found to passivate shallow acceptor impurities causing a dramatic increase in the resistivity of the samples. ${ }^{7,8}$ Also in $n$-type $\mathrm{Si}$, passivation of shallow donor impurities has been seen in experiments. ${ }^{9,10}$ It has also been found that in addition to passivating the existing defects, $\mathrm{H}$ can induce microdefects and electronic deep levels in $\mathrm{Si}^{11}$

Noble-gas impurities in $\mathrm{Si}$ are of special interest because they are used for sputtering, ion etching, and gettering. During these processes, a number of gas atoms are retained in the crystal and may therefore affect the annealing of point defects. Also, the effective use of the thermal-helium-desorption spectroscopy (THDS) ${ }^{12,13}$ requires good knowledge about the effects of $\mathrm{He}$ on defects in $\mathrm{Si}$. The positron-lifetime technique ${ }^{14,15}$ has proved to be very suitable for studies of He in metals. ${ }^{16-20}$ However, such studies on $\mathrm{He}$-implanted $\mathrm{Si}$ have not yet been reported.

In this paper, we present low-temperature positronlifetime measurements of hydrogen $\left(\mathrm{H}^{+}\right)$-implanted and helium-implanted Si. In a previous work by Mäkinen, Rajainmäki, and Linderoth ${ }^{21}$ we reported on positronlifetime studies of $\mathrm{Si}$ irradiated with protons at $15 \mathrm{~K}$.
The samples used in these two studies were cut from the same float-zoned (FZ) single-crystal rod, and the results are therefore highly comparable. In the first paper (henceforth referred to as paper I) we suggested that the main positron traps in the proton-irradiated samples were $V^{-}$and $V_{2} \mathrm{O}^{-}$, and that the specific positron trapping rate $\mu_{+}$to these defects varies as $T^{-0.5}$. In the present work, the same temperature dependence was found in the $\mathrm{H}^{+}$-implanted samples after annealing at $310 \mathrm{~K}$, but in the He-implanted $\mathrm{Si} \mu_{+}$was constant with temperature. The main positron traps in the $\mathrm{H}^{+}$-implanted samples are suggested to be $V^{-}, V_{2}^{-}$, and $V_{2} \mathrm{O}^{-}$. Hydrogen has been assumed to saturate dangling bonds in the monovacancies, and the dissociation of the $\mathrm{Si}-\mathrm{H}$ bonds is suggested to happen at about $550 \mathrm{~K}$. In the $\mathrm{He}$-implanted $\mathrm{Si}$, positrons were mainly trapped by $V_{2}^{0}$ and $V^{0}$.

\section{EXPERIMENTAL}

The single-crystal $\mathrm{Si}$ samples were cut from a floatzoned rod grown at Topsil Semiconductor Materials a/s, Denmark. The impurity concentrations were very low: $5.8 \times 10^{-5} \mathrm{ppm} \mathrm{P}, 2.0 \times 10^{-5} \mathrm{ppm} \mathrm{B},<0.2 \mathrm{ppm} \mathrm{O}$, and $<0.3 \mathrm{ppm}$ C. The material was slightly $n$-type and its resistivity was $2200 \Omega \mathrm{cm}$. The samples were mechanically polished and etched, and samples with thicknesses of $393 \pm 3 \mu \mathrm{m}$ and $387 \pm 1 \mu \mathrm{m}$ were prepared. The sandwich geometry was used for the sample packages, i.e., the ${ }^{22} \mathrm{Na}$ positron source in a thin $\left(1.7 \mathrm{mg} / \mathrm{cm}^{2}\right) \mathrm{Ha}$ var foil envelope was covered by two identical pieces of Si. For more details of the experimental setup, see paper I.

The positron-lifetime spectra contained about 1.1 mil- 
lion events, and the data were analyzed by using the Fortran programs Resolution and Positronfit. ${ }^{22}$ In the analyses of the positron-lifetime spectra, a long-lifetime component of about $1.5 \mathrm{~ns}$ with an intensity of about $0.1 \%$ was detected. We therefore fixed $\tau_{3}$ to $1.5 \mathrm{~ns}$ and $I_{3}$ to $0.1 \%$ in the analyses. The variances of the fits were about 1.0-1.2. The time-resolution function was a one component Gaussian function with a full width at half maximum of $217 \mathrm{ps}$. The total intensity of the source components was found to be $16 \%$ with lifetimes of $170 \mathrm{ps}$ $(13.5 \%)$ and $450 \mathrm{ps}(2.5 \%)$. The positron-lifetime spectra were measured at about $15 \mathrm{~K}$. The stepwise annealings were made with an annealing rate of $25 \mathrm{~K} / \mathrm{h}$.

The $\mathrm{H}^{+}$implantations were performed with $6.95-\mathrm{MeV}$ protons from the backsides of the $387-\mu \mathrm{m}$ Si samples in the sandwich geometry. The sample thickness was sufficient to stop more than $98 \%$ of the positrons within the samples. ${ }^{23}$ The mean penetration depth and the longitudinal straggling of the $6.95-\mathrm{MeV}$ protons are 370 and $6 \mu \mathrm{m}$, respectively. ${ }^{24}$ The proton energy was chosen so that the particles could penetrate to a very close distance from the positron source in order to maximize the overlap of the positrons and the electrons in the implanted region. On the other hand, the proton energy was so low that they could not reach the positron source. The proton beam current was about $100 \mathrm{nA} / \mathrm{cm}^{2}$. Even though this is much more than the current used in the $p$ irradiations $^{21}\left(12 \mathrm{nA} / \mathrm{cm}^{2}\right)$ it still corresponds to the maximum heating power of only $0.2 \mathrm{~W}$. This is not enough to heat the samples significantly when the sample package is connected to the cryocooler with indium.

The width of the implanted region was widened by using $10-\mu \mathrm{m} \mathrm{Al}$ foils as degraders between the MC-20 cyclotron and the sample package. The longitudinal straggling of the $6.95-\mathrm{MeV}$ protons $(6 \mu \mathrm{m})$ suffices to give a quite homogeneous $H$ profile to the implanted region. We used $0-5$ foils, and the final width of the $\mathrm{H}^{+}$. implanted region was, hence, about $65 \mu \mathrm{m}$. The samples were irradiated to a $\mathbf{H}$ concentration of about $28 \mathrm{ppm}$.

Two $396-\mu \mathrm{m}$ Si samples were $\mathrm{He}$ implanted with $25-$ $\mathrm{MeV}{ }^{3} \mathrm{He}^{2+}$ ions to a $\mathrm{He}$ concentration of about $55 \mathrm{ppm}$ by using the similar irradiation procedure as in the former case. In this case the width of the implanted region was extended to about $70 \mu \mathrm{m}$ (by using more Al foils), and the beam current was about $200 \mathrm{nA} / \mathrm{cm}^{2}$.

\section{RESULTS}

\section{A. Hydrogen-implanted $\mathbf{S i}$}

After the $\mathrm{H}^{+}$implantation at $15 \mathrm{~K}$, two positronlifetime components were detected in the samples $(\mathrm{Si}-\mathrm{H})$, in addition to the fixed long lifetime $\tau_{3}$ (Fig. 1). The longer component $\tau_{2}$ was $290 \pm 5$ ps. This is clearly longer than that in the heavily $p$-irradiated Si-II in paper I, where the value of $\tau_{2}(275 \pm 5 \mathrm{ps})$ was connected to positrons that annihilated in monovacancies. The experimentally suggested monovacancy lifetime in $\mathrm{Si}$ is $270-275$ ps, ${ }^{25-27}$ and values of about 320 ps are reported for divancancies in $\mathrm{Si}^{27-29}$ Schaefer et al. ${ }^{30}$ have suggested that the 320-ps lifetime is not due to divacancies only, but

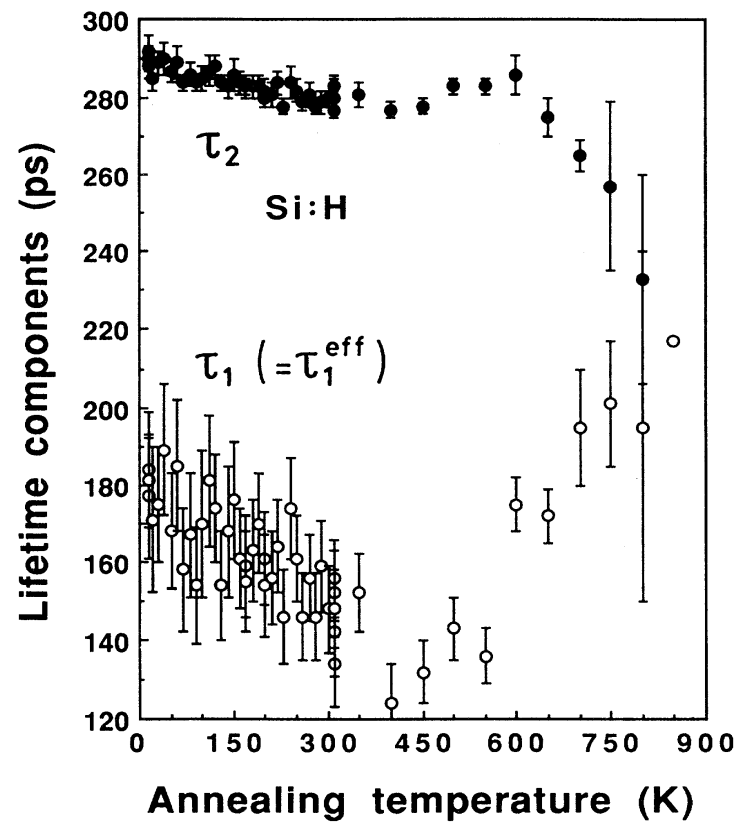

FIG. 1. The positron-lifetime components for the $\mathrm{H}^{+}$implanted $\mathrm{Si}(\mathrm{Si}: \mathrm{H})$ as a function of annealing temperature. The concentration of hydrogen in the $65-\mu \mathrm{m}$-wide implanted region was about $28 \mathrm{ppm}$ after the implantation. The irradiations were carried out at $15 \mathrm{~K}$, and the positron-lifetime spectra were measured at $15 \mathrm{~K}$. See Eq. (4) for the determination of $\tau_{1}^{\text {eff }}$.

also the contribution of larger vacancy agglomerates is important. According to them the positron lifetime in $V_{2}$ might thus be slightly shorter than 320 ps. However, this lifetime is theoretically reproduced by including a reasonable lattice relaxation of $2.8 \%$ outwards around the $V_{2} \cdot{ }^{31}$ Our conclusion is that the implantation produced not only monovacancies in the samples but also a large number of divacancies because $\tau_{2}$ was clearly longer than the monovacancy lifetime of 270-275 ps.

When termalized near a vacancy, protons are suggested to be situated in the high electron density region around the vacancy, not in the center of the vacancy. ${ }^{3,32,33}$ We therefore assume that the implanted protons do not, significantly, affect the electronic structure and the positron lifetime in a vacancy. However, protons may have strong effects on the mobility and annealing of vacancies or vacancy-impurity pairs when associated with these defects.

According to Fig. 2, where the mean positron lifetime $\bar{\tau}$ is shown as a function of annealing temperature, the samples annealed strongly at temperatures between 100 and $300 \mathrm{~K}$. The total irradiation dose used in the $\mathrm{H}^{+}$implantation was about 70 times larger than in the Si-II experiment in paper $I$. Therefore, the intensity of the defect-related lifetime component, $I_{2}$, after the implantation was about $10 \%$ higher than in the former case (see Fig. 3). This intensity is almost constant at the annealing temperatures below $400 \mathrm{~K}$, which could indicate that positron trapping was saturated, at $15 \mathrm{~K}$, through the annealing temperature range of $15-400 \mathrm{~K}$. 


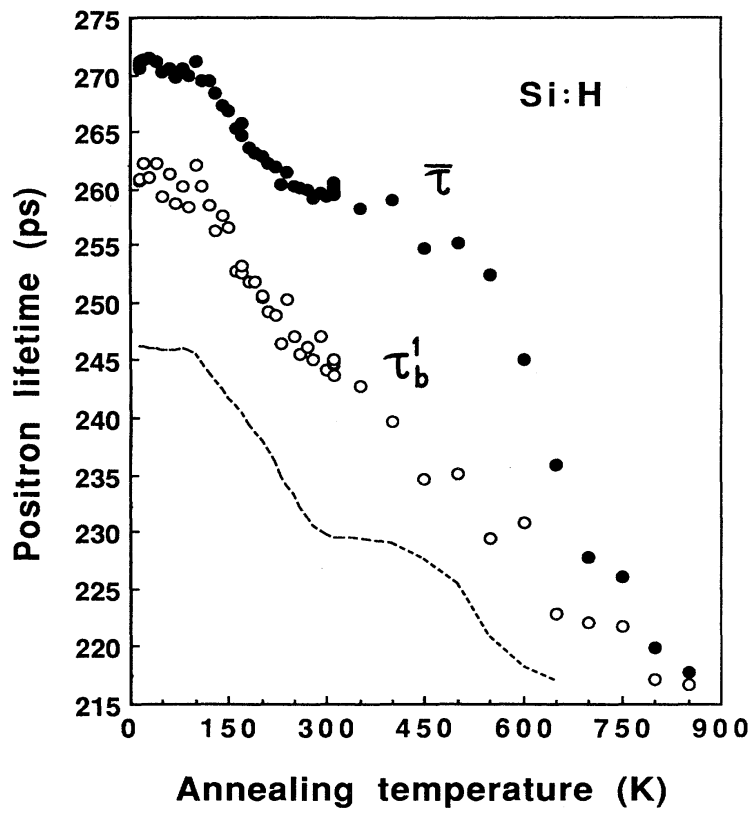

FIG. 2. The mean positron lifetime $\bar{\tau}$ (solid circles) and the bulk lifetime calculated by the one-trap model $\tau_{b}^{1}$ (open circles) as a function of annealing temperature for the $\mathrm{H}^{+}$-implanted $\mathrm{Si}$. The dotted line is the average lifetime vs annealing temperature for the $p$-irradiated Si-II samples (paper I).

In Fig. 2, two clear annealing stages are seen in the mean lifetime: the first at 100 to $300 \mathrm{~K}$ and the other beginning at about $400 \mathrm{~K}$ and lasting up to $850 \mathrm{~K}$. When compared to the proton-irradiated $\mathrm{Si}$ (Si-II in paper I) the 100-300-K annealing stage seems to be much weaker in the $\mathrm{Si}-\mathrm{H}$ samples than in the $\mathrm{Si}-\mathrm{II}$ samples (Fig. 2). How-

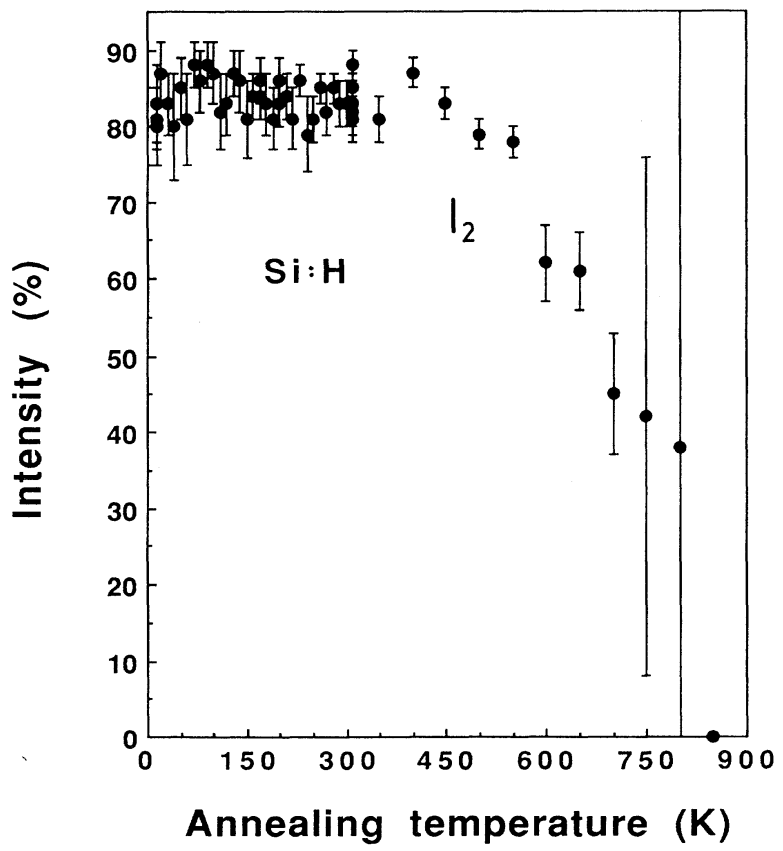

FIG. 3. The intensity of the long-lifetime component $\tau_{2}$ vs annealing temperature for the $\mathbf{H}^{+}$-implanted $\mathrm{Si}$ samples. ever, due to the much larger vacancy concentration in the Si-H samples and due to the sigmoidal dependence of $\bar{\tau}$ on the vacancy concentration, ${ }^{34}$ the weaker decrease in $\bar{\tau}$ does not necessarily mean that the change in the vacancy concentration was any smaller. In paper I, we suggested that the annealing stage at $100-300 \mathrm{~K}$ is due to migration of free, singly negatively charged monovacancies. We adopt this suggestion and propose that this first annealing stage was due to the migration of $V^{-}$.

In the $\mathrm{Si}-\mathrm{H}$ samples the first annealing stage continues up to $850 \mathrm{~K}$, about $250 \mathrm{~K}$ higher than in the Si-II samples. The reason for the delayed annealing is presumably the dissociation of $\mathrm{Si}-\mathrm{H}$ bonds at hydrogen-containing monovacancies. Protons would thus stabilize free monovacancies and hinder them from annealing out at temperatures between 100 and $300 \mathrm{~K}^{21}$ In deuteriumimplanted $\mathrm{Si}$, the annealing out of deuterium-containing monovacancies has been suggested to take place at about $500 \mathrm{~K}{ }^{32}$ In amorphous $\mathrm{Si}$, the $\mathrm{Si}-\mathrm{H}$ bonds have been suggested to break up at about $600 \mathrm{~K}$, and this process is seen to continue up to about $800 \mathrm{~K} .{ }^{35}$ The strong annealing at 550-700 K, seen in Fig. 2, could thus be due to dissociation of $\mathrm{Si}-\mathrm{H}$ bonds in the hydrogenmonovacancy complexes. The possibility of the annealing out of divacancy-hydrogen complexes cannot be excluded.

Another possibility for the long 400-K annealing stage could be the annealing out of singly negatively charged divacancies which is reported to take place at about 550 K. ${ }^{36,37}$ However, it is hard to believe that the annealing of divacancies could last from 550 to $850 \mathrm{~K}$. The length of this stage could also result from the presence of dislocation lines or loops in the samples. The possibility of creating dislocations is now greater than in the case of the proton irradiations because protons are known to produce large cascades of atomic displacements near the region where they stop in a crystal. ${ }^{38}$ The slow annealing at $700-850 \mathrm{~K}$ (Fig. 2) is most probably due to annealing out of vacancies trapped at dislocation lines or loops.

The temperature dependence of the positron-trapping rate $\kappa$ was studied after annealing the $\mathrm{H}^{+}$-implanted $\mathrm{Si}$ samples at $310 \mathrm{~K}$. The behavior was qualitatively the same as for the $p$-irradiated Si samples, ${ }^{21}$ i.e., $\kappa$ was proportional to $T^{-0.5}$. This behavior is expected for negatively charged defects ${ }^{21,39}$ and, thus, indicates that in this case the main positron traps were negatively charged even after annealing at $310 \mathrm{~K}$. This supports the negative charge state of the divacancies, which presumably started to anneal out above $550 \mathrm{~K}$. After the annealings above $310 \mathrm{~K}$, the value of $\tau_{2}$ was significantly lower than the suggested positron lifetime in $V_{2}^{-}(320 \mathrm{ps})$. Therefore, also monovacancy-type defects should have been present in addition to the divacancies. Our conclusion is that, as in the case of the $p$-irradiated $\mathrm{Si}^{21}$ these traps were negatively charged divacancy-oxygen pairs, $V_{2} \mathrm{O}^{-}$. In paper I the annealing out of these pairs was suggested to start at about $400 \mathrm{~K}$, which is consistent with our present results (Fig. 2).

One cannot be sure about the presence of the $V_{2} \mathrm{O}^{-}$defects in the samples, and one should actually bear in mind the possibility of vacancy-carbon complexes also. How- 
ever, the role of carbon on the defect recovery is not known. The $V-P$ pairs are excluded because the concentration of $\mathbf{P}$ is only $5.8 \times 10^{-5} \mathrm{ppm}$.

Our studies about the temperature dependence of the positron-trapping rate clearly indicate negatively charged defects, but Lee and Corbett ${ }^{40}$ have only found neutral $V_{2} \mathrm{O}$ defects in $\mathrm{Si}$ with their EPR studies. Additionally, they only found $V_{2} \mathrm{O}$ defects in Czhoralski-grown (CZ) $\mathrm{Si}$, not in FZ material. This was probably due to the larger concentration of oxygen in the $\mathrm{CZ}$ grown $\mathrm{Si}$ than in the FZ material.

The bulk lifetime calculated by the one-trap model ${ }^{41}$, $\tau_{b}^{1}$, is also shown in Fig. 2. The model fails drastically in reproducing the experimental bulk lifetime of $217 \mathrm{ps}$, and we can conclude that the $\mathrm{Si}-\mathrm{H}$ samples consisted of at least two kinds of positron traps, almost until the end of the annealing process. This supports the existence of dislocations, because they usually anneal out at higher temperatures.

The behavior of the lifetime components as a function of annealing temperature (Fig. 1) is unusual and needs some discussion. Three different kinds of regions can be distinguished. The first starting from $15 \mathrm{~K}$ and lasting up to $100 \mathrm{~K}$ is quite stable (see also Figs. 2 and 3), informing that no annealing takes place in the samples. From 100 to about $400 \mathrm{~K}$ both lifetimes decrease; especially $\tau_{1}$ that decreases by about 45 ps. $\tau_{1}$ should increase towards the bulk lifetime as the samples anneal, if the simple one-trap model ${ }^{41}$ holds. An explanation for the observed behavior can be conducted from the fact that after the implantation the samples consisted of two different kinds of regions from the positron point of view. The first, about a $10-\mu \mathrm{m}$-wide region consisted of perfect $\mathrm{Si}$ crystal where positrons could only annihilate from the delocalized bulk state, resulting in the positron lifetime of 217 ps. Outside this region positrons were able either to annihilate in the bulk or to get trapped by point defects. This gives rise to the modified bulk lifetime $\tau_{1}$ and to the long defectrelated lifetime $\tau_{2}$. The number of positrons at time $t$ can thus be written as

$$
N_{+}(t)=I_{0} e^{-\lambda_{b} t}+I_{1} e^{-\lambda_{1} t}+I_{2} e^{-\lambda_{2} t}
$$

where $I_{0}, I_{1}$, and $I_{2}$ are the intensities of the bulk lifetime $\left(\tau_{b}=1 / \lambda_{b}\right)$, the modified bulk lifetime $\left(\tau_{1}=1 / \lambda_{1}\right)$, and the defect-related lifetime $\left(\tau_{2}=1 / \lambda_{2}\right)$, respectively.

To find out if these two regions can be thought to be separated from the positron point of view, one must think of the diffusion length of positrons at these temperatures. The diffusion length $L_{+}$can be written as $^{42}$

$$
L_{+}=\left(\frac{D_{+}}{\lambda_{b}+\kappa}\right)^{1 / 2},
$$

where $D_{+}$is the diffusion constant, $\lambda_{b}$ is the bulk annihilation rate, and $\kappa$ is the trapping rate of positrons. If we use the one-trap model ${ }^{41}$ to roughly estimate the value of $\kappa$,

$$
\kappa=\frac{\bar{\tau}-\tau_{b}}{\tau_{2}-\bar{\tau}} \lambda_{b}
$$

and a value of $3.0 \mathrm{~cm}^{2} / \mathrm{s}$ for $D_{+}$at $300 \mathrm{~K},{ }^{43}$ we get that $L_{+} \sim 0.1 \mu \mathrm{m}$. If we further take into account that $D_{+} \propto T^{-0.5}$ (Ref. 42), we find that $L_{+} \sim 0.3 \mu \mathrm{m}$ at $15 \mathrm{~K}$. This value is small when compared to the width of the perfect crystal region, and we can conclude that a significant number of positrons only experience perfect crystal before the annihilation.

The intensities of the modified bulk lifetime $\tau_{1}$ and of the defect-related lifetime $\tau_{2}$ can be estimated by calculating the fraction of positrons that were stopped in the 10$\mu \mathrm{m}$-wide region of the perfect $\mathrm{Si}$ crystal. This can be done by using the exponential law for the absorption and by using the formula of Linderoth et al. ${ }^{23}$ for the mass absorption coefficient. This gives that after the implantation $10 \%$ of the positrons emitted by the ${ }^{22} \mathrm{Na}$ source stopped in the defect-free region, i.e., $I_{0}$ is 0.10 in Eq. (1). Thus, $I_{1}$ is $6 \%$, because the value of $I_{2}$ was about $84 \%$ at $15 \mathrm{~K}$ (Fig. 3).

The effective bulk lifetime seen in the measurements $\tau_{1}^{\text {eff }}$ can be determined as

$$
\tau_{1}^{\mathrm{eff}}=\frac{I_{0} \tau_{b}+I_{1} \tau_{1}}{I_{0}+I_{1}},
$$

where $\tau_{b}$ is the bulk lifetime, $\tau_{1}$ is the modified bulk lifetime, and $I_{0}$ and $I_{1}$ are the corresponding intensities, respectively. The value of the modified bulk lifetime at 15 $\mathrm{K}$ can roughly be estimated by using the one-trap model

$$
\frac{1}{\tau_{1}}=\frac{1}{\tau_{b}}+\frac{I_{2}}{I_{1}}\left(\frac{1}{\tau_{b}}-\frac{1}{\tau_{2}}\right),
$$

which gives that $\tau_{1} \approx 50 \mathrm{ps.} \mathrm{If} \mathrm{this} \mathrm{value} \mathrm{is} \mathrm{used} \mathrm{for} \tau_{1}$ in Eq. (4), and if $I_{0}$ and $I_{1}$ are assumed to be 0.10 and 0.06 , respectively, one gets that $\tau_{1}^{\text {eff }}$ is about 155 ps. As can be seen in Fig. 1, this is close to the value of the short lifetime component seen in our measurements.

As the annealing temperature exceeds $100 \mathrm{~K}$ the free, singly negatively charged monovacancies become mobile and some of them begin to penetrate through the region of the perfect crystal, in order to get to the surface of the sample. The migrating monovacancies can then be trapped by some impurity atoms, forming vacancyimpurity pairs; also in the $10-\mu \mathrm{m}$-wide region of perfect $\mathrm{Si}$. In this region, the density of positrons is very high due to the exponential absorption. The relative number of positrons that annihilate at the bulk state thus decreases strongly, giving rise to the decrease of the shortlifetime component $\tau_{1}^{\text {eff }}$ seen in Fig. 1. As in the Si-II experiment in paper $I$, these vacancy-impurity complexes are suggested to be singly negatively charged divacancyoxygen pairs, $V_{2} \mathrm{O}^{-}$, because the final annealing step started at the same temperature of $400 \mathrm{~K}$ in these two experiments. We conclude that the decrease seen in the short-lifetime component at temperatures between 100 and $400 \mathrm{~K}$ is due to the decrease in the number of positrons that annihilate in the perfect crystal closest to the positron source.

Another explanation for the unusual behavior of $\tau_{1}$ would be the trapping of positrons by, e.g., interstitial clusters. One can assume that at these defects the positron lifetime is close to the bulk lifetime, and that the 
modified bulk lifetime would then easily be mixed to this lifetime component in the analysis, resulting in the $\tau_{1}$ component of Fig. 1. If the number of these defects decreased as the annealing temperatures increased from 15 to $400 \mathrm{~K}$, the values of $\tau_{1}$ would behave as seen in our analysis (Fig. 1). This explanation assumes that the interstitial clusters trap positrons at the measuring temperature of $15 \mathrm{~K}$. The existence of two different kinds of traps would also lead to the observed low values of $I_{2}$ in the saturated state.

Also the long-lifetime component $\tau_{2}$ decreased as the annealing temperature went from 100 to $400 \mathrm{~K}$ (Fig. 1). This might be due to a different kind of atomic relaxation around a pure monovacancy and around a $V_{2} \mathrm{O}^{-}$pair. If the positron lifetime at a pure monovacancy was a few picoseconds longer than at a $V_{2} \mathrm{O}^{-}$pair, the decrease in $\tau_{2}$ would just be a consequence of the decrease in the relative number of positrons annihilating at pure monovacancies as the free monovacancies migrate and trap at monovacancy-oxygen pairs, $V(\mathrm{O})$.

At $400 \mathrm{~K}$, the migration of monovacancies is finished and $\tau_{1}$ begins to grow (Fig. 1). Also $\tau_{2}$ rises by about 10 ps as the annealing temperature goes from 400 to $600 \mathrm{~K}$. This could indicate that divacancies were formed when the $V_{2} \mathrm{O}^{-}$pairs broke up. Above $600 \mathrm{~K} \tau_{2}$ starts to decrease, while the increase in $\tau_{1}$ proceeds, which indicates that $\tau_{1}$ and $\tau_{2}$ were connected to each other in the analysis of the positron-lifetime spectra, as also follows from the trapping model. ${ }^{41}$

\section{B. He-implanted Si}

Two identical 396- $\mu$ m-thick Si samples were implanted by $25-\mathrm{MeV}{ }^{3} \mathrm{He}^{2+}$ ions at $15 \mathrm{~K}$ to a $\mathrm{He}$ concentration of

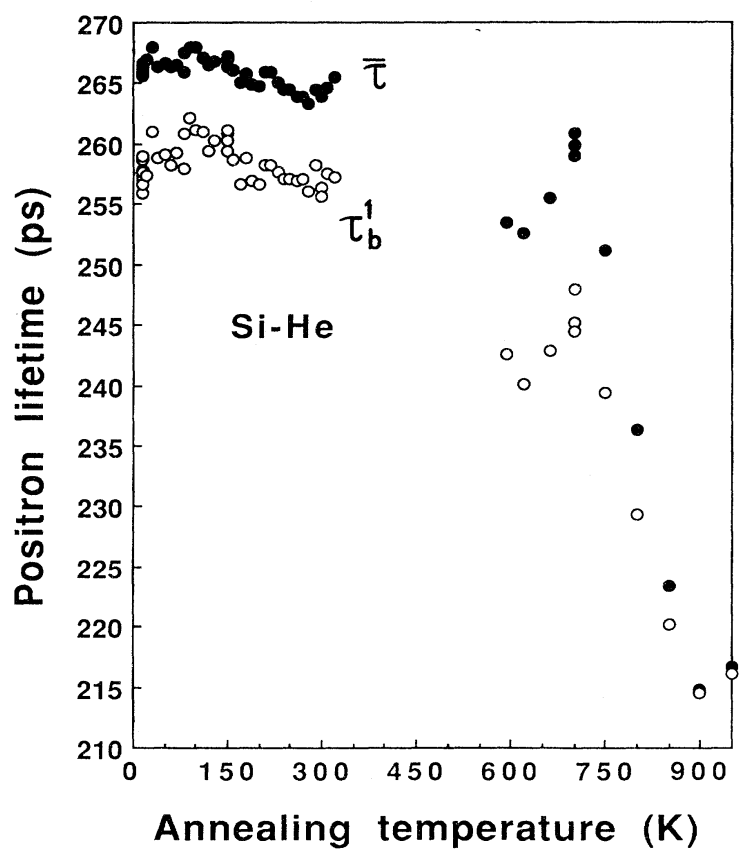

FIG. 4. The mean positron lifetime $\bar{\tau}$ (solid circles) and the bulk lifetime calculated by the one-trap model $\tau_{b}^{1}$ (open circles) as a function of annealing temperature for the $\mathrm{He}$-implanted $\mathrm{Si}$. about $55 \mathrm{ppm}$. The reason for using ${ }^{3} \mathrm{He}$ instead of ${ }^{4} \mathrm{He}$ was a solely technical one; the maximum kinetic energy that can be achieved for ${ }^{4} \mathrm{He}$ by the MC-20 cyclotron is $20 \mathrm{MeV}$ which was insufficient for our experiment. Furthermore, ${ }^{3} \mathrm{He}$ ions are more penetrating than ${ }^{4} \mathrm{He}$ ions.

In Fig. 4, the mean positron lifetime is plotted against annealing temperature. After the 320-K annealing the samples were accidentally annealed at $320{ }^{\circ} \mathrm{C}(593 \mathrm{~K})$, which is seen in the figure as a lack of data point between 320 and $593 \mathrm{~K}$. Fortunately, no drastic changes in the positron-lifetime parameters seem to have happened in this temperature range - although the 400-K annealing step, seen in the Si-II and Si-H experiments, could thereby not be studied in this case.

No annealing can be distinguished at temperatures between 100 and $300 \mathrm{~K}$, in contrast to the $p$-irradiated and $\mathrm{H}^{+}$-implanted $\mathrm{Si}$. Another interesting phenomenon is that $\tau_{1}$ was very high after the implantation, about $220 \mathrm{ps}$ (Fig. 5). This is close to the positron lifetime in the perfect lattice $(217 \mathrm{ps})$, although defect trapping should lead to a $\tau_{1}$ considerably lower than the bulk lifetime. An explanation for this could be the existence of irradiationinduced monovacancy-He complexes, giving rise to a positron lifetime close to the bulk lifetime. If this lifetime was mixed to the modified bulk lifetime in the analysis of the positron-lifetime spectra, and if the number of these complexes was high enough, the experimentally seen short-lifetime component could be close to the perfect lattice lifetime. Also the relatively low $I_{2}$ values (Fig. 6) after the irradiation suggest this assumption.

We estimated the positron lifetime at a monovacancy-

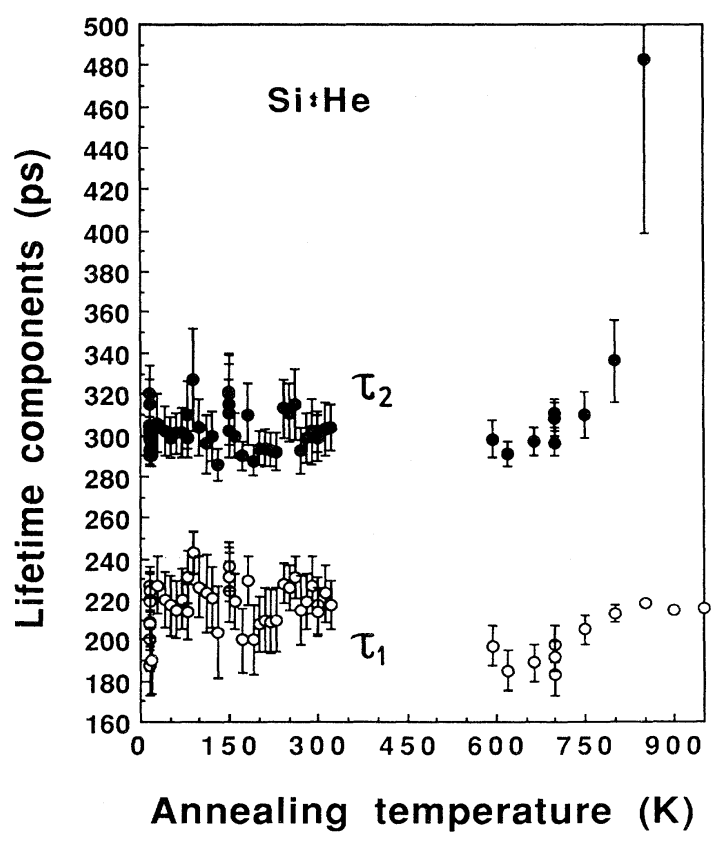

FIG. 5. The positron-lifetime components for the $\mathrm{He}$ implanted $\mathrm{Si}(\mathrm{Si}: \mathrm{He})$ as a function of annealing temperature. The concentration of $\mathrm{He}$ was about $55 \mathrm{ppm}$ in the implanted region of $70 \mu \mathrm{m}$. The irradiations were performed with ${ }^{3} \mathrm{He}^{2+}$ ions at $15 \mathrm{~K}$. 


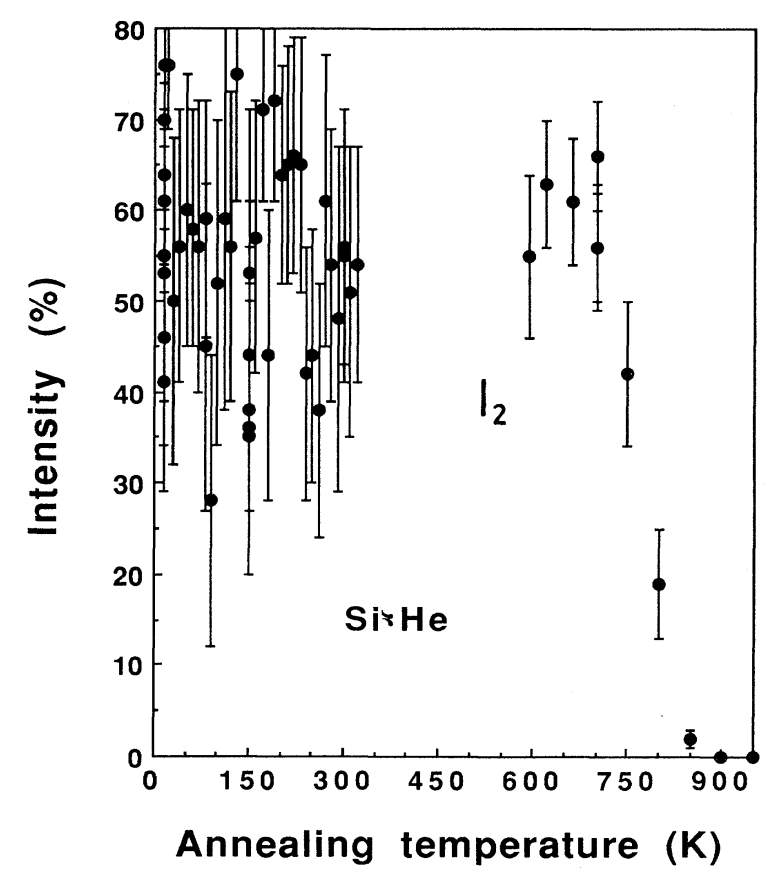

FIG. 6. The intensity of the defect-related lifetime component $\tau_{2}$ vs annealing temperature for the He-implanted $\mathrm{Si}$.

He pair by calculating the positron-annihilation characteristics at a $\mathrm{Si}$ monovacancy containing a $\mathrm{He}$-atom in the middle of the vacancy. The calculations were performed by using the model of Puska and Nieminen ${ }^{44}$ with no atomic relaxation around the vacancy. According to these calculations, the positron is trapped at this defect with a binding energy of about $0.14 \mathrm{eV}$, and it results in a positron lifetime of about 227 ps. This explains the long $\tau_{1}$ values seen in the Si-He samples (Fig. 5), which in all probability are mixtures of the modified bulk lifetime, due to positrons that were trapped at monovacancies in the He-free region, and of the lifetime of positrons annihilating in He-containing monovacancies. The contour plots of the positron wave function localized at a monovacancy, a divacancy, and a monovacancy containing a He-atom are shown in Fig. 7.

After the He-implantation, the value of the defectrelated lifetime component $\tau_{2}$ was about 300 ps, significantly longer than in the proton-irradiated and $\mathbf{H}^{+}$-implanted samples. This lifetime is suggested to be due to positrons trapped at divacancies. The experimentally suggested divacancy lifetime in $\mathrm{Si}$ is about 320 ps. ${ }^{27-29}$

The temperature dependence of the positron-trapping rate was studied after annealing the Si-He samples at 80 and at $300 \mathrm{~K}$. No changes were observed in $\kappa$ as a function of the measuring temperature. This indicates that in this case the charge state of the main positron traps was neutral, in contrast to the $p$-irradiated and $\mathbf{H}^{+}$-implanted samples, where the $T^{-0.5}$ dependence of $\kappa$ suggests for negatively charged defects.

At temperatures between 600 and $700 \mathrm{~K}, \bar{\tau}$ increases by about 7 ps (Fig. 4). We suggest that heliummonovacancy pairs were dissociated at these tempera-

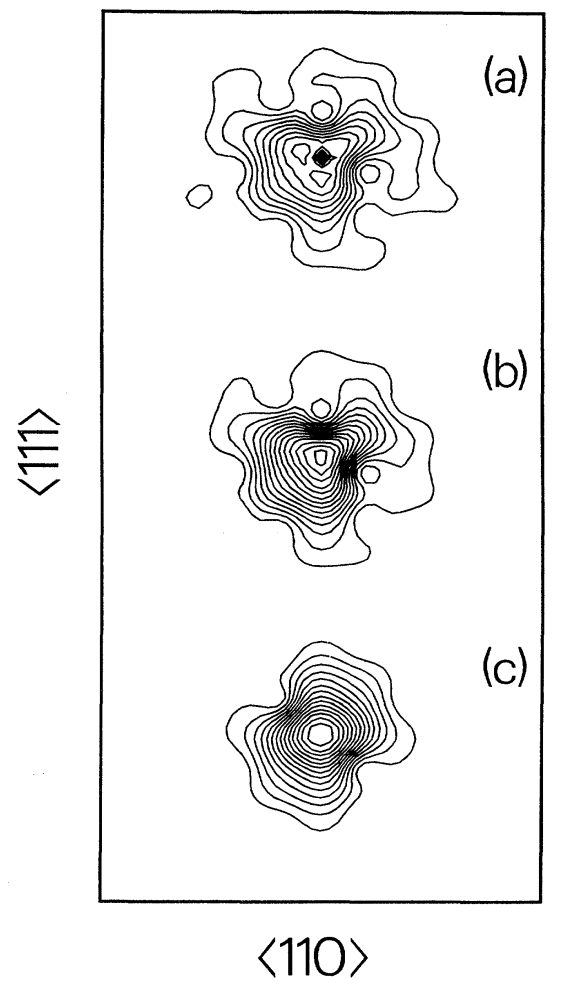

FIG. 7. Contour plots of the positron wave function localized at (a) a $\mathrm{Si}$ monovacancy including a $\mathrm{He}$ atom, (b) at a monovacancy, and (c) at a divacancy. Atomic relaxation around the vacancy was not included in the calculations, and the vacancy charge state was neutral.

tures, leaving the vacancies free to migrate, to be lost at sinks or to agglomerate. At $700 \mathrm{~K}, \bar{\tau}$ and $I_{2}$ start to decrease strongly as the final annealing begins. At the same time as $I_{2}$ goes down, $\tau_{2}$ starts to increase, reaching a value of about $480 \mathrm{ps}$ at $850 \mathrm{~K}$. This could mean that $\mathrm{He}$ bubbles were created in the samples. However, the value of $I_{2}$ is only about $2 \%$ for the 480 -ps lifetime. The value of $\tau_{2}$ is already high at $800 \mathrm{~K}$, about $335 \mathrm{ps}$, with a remarkable intensity of $19 \pm 6 \%$. We thus assume that cavities, probably small $\mathrm{He}$ bubbles, were grown in the samples at temperatures above $800 \mathrm{~K}$.

Gorelkinskii, Nevinny, and Ajazbaev ${ }^{45}$ have studied ${ }^{3} \mathrm{He}$-implanted Si by using the EPR technique, and found two EPR active centers that anneal out at about $450 \mathrm{~K}$. They tentatively suggested that these centers are due to neutral vacancy-He complexes. Unfortunately, we cannot draw any clear conclusions about this temperature region because of the accidental annealing at $593 \mathrm{~K}$ after $320 \mathrm{~K}$. Also THDS and transmission electron microscopy have been used to study He-implanted $\mathrm{Si}^{46,47}$ However, these studies have dealt with large cavities and blistering effects, and the annealing out of monovacancies or divacancies have not been studied.

\section{CONCLUSIONS}

Single-crystal Si samples were implanted with 6.95$\mathrm{MeV}$ protons and with $25-\mathrm{MeV}{ }^{3} \mathrm{He}^{2+}$ ions, and the in- 
teractions of $\mathrm{H}$ and $\mathrm{He}$ with the irradiation-induced defects were studied by using the positron-lifetime technique. Nothing was found to happen at temperatures between 15 and $100 \mathrm{~K}$. In the $\mathrm{H}^{+}$-implanted samples a strong annealing step was seen at 100 to $300 \mathrm{~K}$. This stage is connected to the annealing out of free, singly negatively charged monovacancies. At $300-400 \mathrm{~K}$ the vacancy concentrations were more or less unchanged, and the final annealing step started at about $400 \mathrm{~K}$. At temperatures above $400 \mathrm{~K}$, divacancy-oxygen pairs are suggested to anneal out. The $\mathrm{Si}-\mathrm{H}$ bonds in hydrogencontaining monovacancies are suggested to break up above $550 \mathrm{~K}$. Also singly negatively charged divacancies are believed to anneal out above $550 \mathrm{~K}$. The last annealing at $700-850 \mathrm{~K}$ is most probably due to the escape of vacancies from dislocation lines or loops created in the samples during the implantation.
In the He-implanted Si no annealing was seen at temperatures between 100 and $300 \mathrm{~K}$, indicating that nearly all monovacancies contained $\mathrm{He}$ and that the concentration of free monovacancies was therefore very small. Helium is suggested to be released from vacancies at about $600 \mathrm{~K}$. Small He bubbles may have grown at temperatures above $800 \mathrm{~K}$.

\section{ACKNOWLEDGMENTS}

The authors want to thank M. Manninen, M. J. Puska, and P. Hautojärvi for many helpful discussions. We are also grateful to T. Visler at Topsil Semiconductor Materials a/s for the Si samples and for the impurity analysis. One of us (S.M.) wants to thank the Emil Aaltonen foundation for financial support.
*Present address: Outokumpu Poricopper Oy, P. O. Box 60, SF-28101 Pori, Finland.

${ }^{1}$ Proceedings of the Fifteenth International Conference on Defects in Semiconductors, Hungary, 1988, Materials Science Forum, Vols. 38-41, edited by G. Ferenczi (Trans Tech, Ltd, Aedermannsdorf, Hungary, 1989).

${ }^{2}$ G. G. DeLeo, W. B. Fowler, and G. D. Watkins, Phys. Rev. B 29, 1819 (1984).

${ }^{3}$ S. J. Pearton, M. Stavola, and J. W. Corbett, in the Proceedings of the Fifteenth International Conference on Defects in Semconductors, 1988, Ref. 1, p. 25.

${ }^{4}$ S. K. Estreicher, L. Throckmorton, and D. S. Marynick, Phys. Rev. B 39, 13241 (1989).

${ }^{5}$ G. Müller, Appl. Phys. A 45, 41 (1988); Phys. Rev. B 39, 13241 (1989).

${ }^{6}$ S. J. Pearton, J. W. Corbett, and T. S. Shi, Appl. Phys. A 43, 153 (1987).

7J. I. Pankove, D. E. Carlson, J. E. Berkeyheiser, and R. O. Wance, Phys. Rev. Lett. 51, 2224 (1983).

${ }^{8}$ C. T. Sah, J. Y.-C. Sun, and J. J.-T. Tzou, Appl. Phys. Lett. 43, 204 (1983).

${ }^{9}$ N. M. Johnson, C. Herring, and D. J. Chadi, Phys. Rev. Lett. 56, 769 (1986).

${ }^{10}$ K. Bergman, M. Stavola, S. J. Pearton, and J. Lopata, Phys. Rev. B 37, 2770 (1988).

${ }^{11}$ N. M. Johnson, F. A. Ponce, R. A. Street, and R. J. Nemanich, Phys. Rev. B 35, 4166 (1987).

${ }^{12}$ A. A. van Gorkum and E. V. Kornelsen, Vacuum 31, 89 (1981).

${ }^{13}$ E. V. Kornelsen and A. A. van Gorkum, Vacuum 31, 99 (1981).

${ }^{14}$ Positrons in Solids, edited by P. Hautojärvi, Topics in Current Physics, Vol. 12 (Springer, Heidelberg, 1979).

${ }^{15}$ Positron Solid State Physics, Proceedings of the Enrico Fermi International School of Physics, "Enrico Fermi," Course LXXXIII, Varenna, 1981, edited by W. Brandt and A. Dupasquier (North-Holland, Amsterdam, 1983).

${ }^{16}$ C. L. Snead, A. N. Goland, and F. W. Wiffen, J. Nucl. Mater. 64, 195 (1977).

${ }^{17}$ H. Rajainmäki, S. Linderoth, H. E. Hansen, R. M. Nieminen, and M. D. Bentzon, Phys. Rev. B 38, 1087 (1988).

${ }^{18}$ H. E. Hansen, H. Rajainmäki, R. Talja, M. D. Bentzon, R. M. Nieminen, and K. Petersen, J. Phys. F 15, 1 (1985).
${ }^{19}$ K. O. Jensen and R. M. Nieminen, Phys. Rev. B 36, 8219 (1987).

${ }^{20}$ K. O. Jensen, M. Eldrup, B. N. Singh, and M. Victoria, J. Phys. F 18, 1069 (1988).

${ }^{21}$ S. Mäkinen, H. Rajainmäki, and S. Linderoth, Phys. Rev. B 42, 11166 (1990) (paper I).

${ }^{22}$ P. Kirkegaard, M. Eldrup, O. E. Mogensen, and N. J. Pedersen, Comput. Phys. Commun. 23, 307 (1981).

${ }^{23}$ S. Linderoth, H. E. Hansen, B. Nielsen, and K. Petersen, Appl. Phys. A 33, 25 (1984).

${ }^{24}$ U. Littmark and J. F. Ziegler, Handbook of Range Distributions for Energetic Ions in All Elements (Pergamon, New York, 1980).

25J. Mäkinen, C. Corbel, P. Hautojärvi, P. Moser, and F. Pierre, Phys. Rev. B 39, 10162 (1989).

${ }^{26}$ R. Würschum, W. Bauer, K. Maier, A. Seeger, and H.-E. Schaefer, J. Phys. Condens. Matter 1, SA33 (1989).

${ }^{27}$ S. Dannefaer, G. W. Dean, D. P. Kerr, and B. G. Hogg, Phys. Rev. B 14, 2709 (1976).

${ }^{28}$ W. Fuhs, U. Holzhauser, S. Mantl, F. W. Richter, and R. Sturm, Phys. Status Solidi. B 89, 69 (1978).

${ }^{29} \mathrm{~S}$. Dannefaer, in Proceedings of the Eighth International Conference on Positron Annihilation, Gent, Belgium, 1988, edited by L. Dorikens-Vanpraet, M. Dorikens, and D. Segers (World Scientific, Singapore, 1989), p. 86.

${ }^{30}$ H.-E. Schaefer, R. Würschum, R. Schwarz, D. Slobodin, and S. Wagner, Appl. Phys. A 40, 145 (1986).

${ }^{31}$ S. Mäkinen and M. J. Puska, Phys. Rev. B 40, 12523 (1989).

${ }^{32}$ B. Bech Nielsen, Ph.D. thesis, University of Aarhus (1987); see also B. Bech Nielsen, Phys. Rev. B 37, 6353 (1988).

${ }^{33}$ V. A. Singh, C. Weigel, J. W. Corbett, and L. M. Roth, Phys. Status. Solidi. 81, 637 (1977); see also S. T. Picraux and F. L. Vook, Phys. Rev. B 18, 2066 (1978).

${ }^{34}$ G. Dlubek, O. Brümmer, F. Plazaola, and P. Hautojärvi, Phys. C 19, 331 (1986).

${ }^{35}$ H. J. Stein and P. S. Peercy, Phys. Rev. B 22, 6233 (1980).

${ }^{36}$ G. D. Watkins, in Deep Centers in Semiconductors, A State-ofthe-Art Approach, edited by S. T. Pantelides (Gordon and Breach, New York, 1986), p.147.

${ }^{37}$ J. W. Corbett, J. K. Karins, and T. Y. Tan, Nucl. Instrum. Methods 182\&183, 457 (1981).

${ }^{38}$ J. Keinonen, M. Hautala, E. Rauhala, M. Erola, J. Lahtinen, H. Huomo, A. Vehanen, and P. Hautojärvi, Phys. Rev. B 36, 
1344 (1987); J. Keinonen, M. Hautala, E. Rauhala, V. Karttunen, A. Kuronen, J. Räisänen, J. Lahtinen, A. Vehanen, E. Punkka, and P. Hautojärvi, ibid. 37, 8269 (1988).

${ }^{39}$ M. J. Puska, C. Corbel, and R. M. Nieminen, Phys. Rev. B 41, 9980 (1990).

${ }^{40}$ Y.-H. Lee and J. W. Corbett, Phys. Rev. B 13, 2653 (1976).

${ }^{41}$ See, e.g., R. N. West, in Positrons in Solids, edited by $\mathbf{P}$. Hautojärvi, Topics in Current Physics, Vol. 12, (Springer, Heidelberg, 1979), p. 89.

${ }^{42}$ K. G. Lynn, in Positron Solid State Physics, Proceedings of the Enrico Fermi International School of Physics, "Enrico Fermi”, Course LXXXIII, Varenna, 1981, edited by W. Brandt and A. Dupasquier (North-Holland, Amsterdam, 1983),p. 609.

43J. Mäkinen, C. Corbel, P. Hautojärvi, A. Vehanen, and D. Mathoit, Phys. Rev. B 43, 12114 (1991).

${ }^{44}$ M. J. Puska and R. M. Nieminen, J. Phys. F 13, 333 (1983), M. J. Puska, Phys. Status. Solidi. A 102, 11 (1987).

${ }^{45}$ Yu. V. Gorelkinskii, N. N. Nevinnyi, and S. S. Ajazbaev, Phys. Lett. 110A, 157 (1985).

${ }^{46}$ C. C. Griffioen, J. H. Evans, P. C. DeJong, and A. van Veen, Nucl. Instrum. Methods B 27, 417 (1987).

${ }^{47}$ J. H. Evans, A. van Veen, and C. C. Griffioen, Nucl. Instrum. Methods B 28, 360 (1987). 